\title{
Aneurysm of left ventricle and left coronary artery after non-penetrating chest trauma
}

\author{
DAVID L STONE, HUGH A FLEMING \\ From the Regional Cardiac Unit, Papworth Hospital, Papworth Everard, Cambridge
}

SUMMARY A 17 year old boy who sustained blunt chest trauma to his chest developed a proximal left anterior descending coronary artery aneurysm and an aneurysm of the left ventricle. He underwent left ventricular aneurysmectomy and was discharged to outpatient follow up.

Attention has recently been drawn to the occurrence of cardiac damage as a result of non-penetrating chest injury. ${ }^{1-3}$ We describe a case of blunt chest trauma which resulted in aneurysms of the left ventricle and left anterior descending coronary artery. Although coronary arteries may be damaged by blunt chest trauma, ${ }^{45}$ the development of an aneurysm has been reported only in penetrating injuries. ${ }^{6}$

\section{Case report}

A 17 year old bank clerk was admitted to Addenbrookes Hospital after a motor cycle accident with multiple injuries including a compound tibial fracture. No evidence of chest trauma was found, but splenectomy was performed for intra-abdominal bleeding. The next day the patient became breathless with sinus tachycardia, and chest $x$ ray examination confirmed pulmonary oedema. The electrocardiogram showed $\mathrm{Q}$ waves and ST segment elevation consistent with transmural anterior myocardial infarction. Treatment with digitalis and diuretics was started and, although the sinus tachycardia was slow to settle, the patient was discharged to follow up on this treatment. The patient returned to work and became fully mobile.

Five years later he began to notice breathlessness on extra exertion, which limited him to some degree. The appearance on the electrocardiogram of transmural myocardial infarction and the clinical and radiological features of left ventricular aneursym had persisted. Equilibrium gated radionuclide ventriculography showed changes consistent with an apical aneurysm. Overall ejection fraction was $50 \%$ at rest and $66 \%$ on exercise. In view of his symptoms the patient was investigated by cardiac catheterisation. Contrast ventriculography confirmed the radionuclide findings of a left ventricular aneurysm. Coronary arteriography showed a discrete proximal aneurysm of the left anterior descending coronary artery (Fig.). The rest of the left coronary artery was normal, as was the right coronary artery.

The patient was referred to $\mathrm{Mr}$ TAH English, who performed a left ventricular aneurysmectomy. The aneurysm of the coronary artery was palpated high in the anterior interventricular groove and was soft. Its position was too proximal to allow surgical removal, and the patient was discharged to outpatient follow up.

\section{Discussion}

Non-penetrating trauma can result in serious damage to the left ventricular wall, heart valves, pericardium, and coronary arteries. ${ }^{1-3}$ Mackintosh and Fleming ${ }^{1}$ recently reported a series of cases highlighting certain aspects of cardiac damage and emphasised the fact that the diagnosis is often delayed. This report elaborates the findings of one of their cases. The diagnosis was not made immediately, and it was only after the development of acute left ventricular failure that the presence of cardiac damage was suspected. The electrocardiographic changes were those of myocardial infarction. Early studies ${ }^{7}$ reported cases of myocardial damage due to indirect cardiac trauma, and Parmley et al. ${ }^{8}$ emphasise the importance of screening for cardiac damage in any case of nonpenetrating trauma. They also suggest, however, that myocardial contusion is always direct and that cardiac damage is rarely secondary to coronary arterial thrombosis. More recently, other papers have suggested that coronary damage may indeed occur, especially in the presence of previous coronary artery disease..$^{9-11}$

The case described here shows clearly that damage to the artery has occurred. The coronary artery 


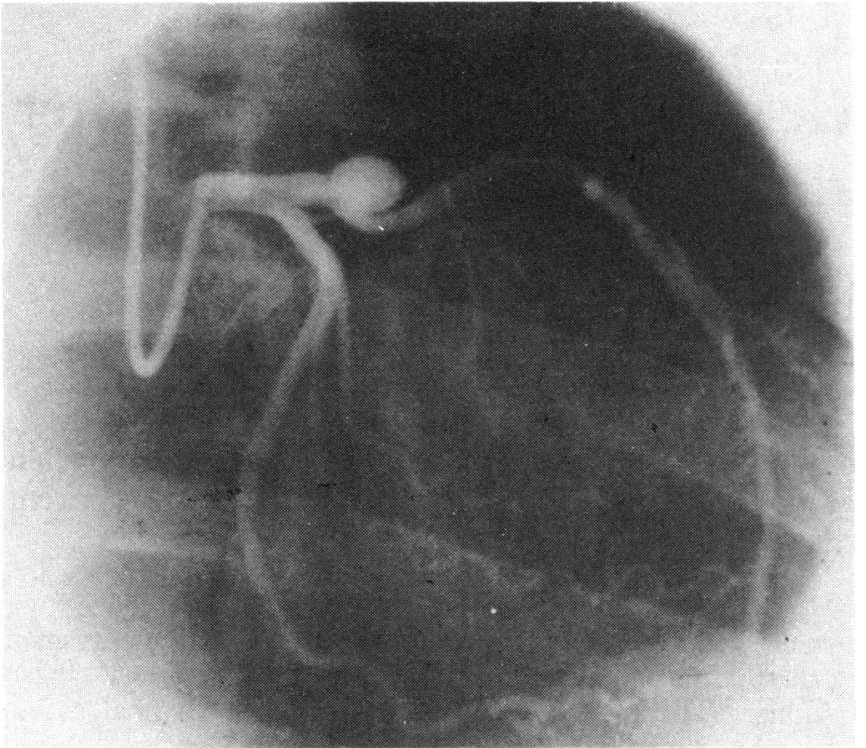

Fig. Left coronary arteriogram showing the proximal discrete aneurysm.

aneurysm found at catheterisation was single, and there was no evidence of any other coronary artery lesions or aneurysms. In such a young patient we must assume that the coronary artery aneurysm was due to the trauma and that the left ventricular damage was secondary. We can find no other reports of coronary aneurysm formation after blunt chest trauma, although Konecke et al. ${ }^{6}$ reported a case of left anterior descending aneurysm due to a bullet wound. They managed the coronary artery aneurysm conservatively, as we did in this patient.

Left ventricular aneurysm may result from blunt or penetrating cardiac trauma. ${ }^{1213}$ Although the coronary arterial damage was almost certainly the primary event, this case is unique in that aneurysms of the coronary artery and left ventricle developed in one patient after a single trauma. The non-invasive radionuclide investigation provided good evidence of a ventricular aneurysm, which was confirmed at cardiac catheterisation and subsequent operation.

This case shows the importance of considering cardiac damage when dealing with a case of blunt trauma. Electrocardiographic changes have been shown in $38 \%$ of a series of patients with nonpenetrating chest trauma, ${ }^{14}$ and Fox et al. ${ }^{15}$ described four cases with electrophysiological manifestations of blunt cardiac injury. This may have important implications in terms of both prognosis and management of a patient with chest injury and for assessment of donors for heart transplantation.

Since submitting the paper the patient has had a cerebrovascular accident, presumably embolic from the aneurysmectomy scar.
References

1 Mackintosh AF, Fleming HA. Cardiac damage presenting late after road accidents. Thorax 1981; 36: 811-3.

2 Liedtke AJ, DeMuth WE Jr. Non-penetrating cardiac injuries: a collective review. Am Heart $\mathcal{f}$ 1973; 86: 68797.

3 Symbas PN. Cardiac trauma. Am Heart $\mathcal{f}$ 1976; 92: $387-96$.

4 Stewart JSS. Primary traumatic coronary thrombosis. $\mathrm{Br}$ Med F 1967; i: 739-40.

5 Heyndrickx G, Vermeire P, Goffin Y, Van den Bogaert $P$. Rupture of the right coronary artery due to nonpenetrating chest trauma. Chest 1974; 65: 577-9.

6 Konecke LL, Spitzer S, Mason D, Kasparian H, James PM Jr. Traumatic aneurysm of the left coronary artery. Am $\mathcal{F}$ Cardiol 1971; 27: 221-3.

7 Boas EP. Angina pectoris and cardiac infarction from trauma or unusual effort. $\mathcal{F A M A} 1$ 1939; 112: 1887-92.

8 Parmley LF, Manion WC, Mattingly TW. Non penetrating traumatic injury of the heart. Circulation 1958; 18; 371-96.

9 Vlay SC, Blumenthal DS, Shoback D, Fehir K, Bulkley BH. Delayed acute myocardial infarction after blunt chest trauma in a young woman. Am Heart $\mathcal{F} 1980 ; 100$ : 907-16.

10 Oren A, Bar-Shlomo B, Stern S. Acute coronary occlusion following blunt injury to the chest in the absence of coronary atherosclerosis. Am Heart 1976; 92: 501-5.

11 Lehmus HJ, Sundquist AB, Giddings LW. Coronary thrombosis with myocardial infarction secondary to non-penetrating injury of the chest wall. Am Heart $\mathcal{f}$ 1954; 47: 470-3.

12 Killen DA, Gobbel WG Jr, France R, Vix VA. Post traumatic aneurysm of the left ventricle. Circulation $1969 ; 39 ; 101-8$. 
13 Aronstam EM, Strader LD, Geiger JP, Gomez AC. Traumatic left ventricular aneurysms. $\mathcal{F}$ Thorac Cardiovasc Surg 1970; 59: 239-42.

14 Watson JH, Bartholomae WM. Cardiac injury due to non-penetrating chest trauma. Ann Intern Med 1960; 52: 871-80.

15 Fox KM, Rowland E, Krikler DM, Bentall HH, Good- win JF. Electrophysiological manifestations of nonpenetrating cardiac trauma. Br Heart $\mathcal{F} 1980$; 43: 458-62.

Requests for reprints to Dr David L Stone, Regional Cardiac Unit, Papworth Hospital, Papworth Everard, Cambridge CB3 8RE.

\section{Notice}

\section{British Cardiac Society}

The Autumn Meeting will be held at Wembley on 21 and 22 November 1983, and the closing date for abstracts was 26 July 1983.

The Annual General Meeting for 1984 will take place in Leicester on 11 and 12 April 1984, and the closing date for receipt of abstracts will be 3 January 1984.

The Autumn Meeting in 1984 will be held on 3 and 4 December 1984, and the closing date for receipt of abstracts will be 15 August 1984 .

\section{Corrigendum}

We regret the following errors in the paper in the August issue by Dr E J Perrins and others on randomised controlled trial of physiological and ventricular pacing (p 112). In the footnote to Table $1 \mathrm{CHB}$ should read complete heart block and COCM should read congestive cardiomyopathy. 